Check for updates

Cite this: RSC Adv., 2018, 8, 41101

Received 7th September 2018

Accepted 20th November 2018

DOI: $10.1039 / \mathrm{c} 8 \mathrm{ra07483f}$

rsc.li/rsc-advances

\section{Rapid fabrication of porous silicon/carbon microtube composites as anode materials for lithium-ion batteries}

\begin{abstract}
Shuxian Wang, (DD a Chunlai Huang, ${ }^{\text {ab }}$ Lei Wang, ${ }^{\text {*a }}$ Wei Sun ${ }^{\mathrm{c}}$ and Deren Yang ${ }^{\mathrm{a}}$
Herein, we present a simple and rapid method to synthesize porous silicon/carbon microtube composites (PoSi/CMTs) by adopting a unique configuration of acid etching solution. The CMTs can act as both conductive agent and buffer for Si volume change during the charge and discharge process. The highly reversible capacity and excellent rate capability can be ascribed to the structure, where porous silicon powders are wrapped by a network of interwoven carbon microtubes. The composites show specific capacities of more than $1712 \mathrm{~mA} \mathrm{~h} \mathrm{~g}^{-1}$ at a current density of $100 \mathrm{~mA} \mathrm{~g}^{-1}, 1566 \mathrm{~mA} \mathrm{~h} \mathrm{~g}^{-1}$ at $200 \mathrm{~mA} \mathrm{~g}^{-1}, 1407 \mathrm{~mA} \mathrm{~h} \mathrm{~g}^{-1}$ at $400 \mathrm{~mA} \mathrm{~g}^{-1}, 1177 \mathrm{~mA} \mathrm{~h} \mathrm{~g}^{-1}$ at $800 \mathrm{~mA} \mathrm{~g}^{-1}, 1107 \mathrm{~mA} \mathrm{~h} \mathrm{~g}^{-1}$ at $1000 \mathrm{~mA} \mathrm{~g}^{-1}, 798 \mathrm{~mA} \mathrm{hg}^{-1}$ at $2000 \mathrm{~mA} \mathrm{~g}^{-1}$, and $581 \mathrm{~mA} \mathrm{~h} \mathrm{~g}^{-1}$ at $3000 \mathrm{~mA} \mathrm{~g}^{-1}$ and maintain a value of $1127 \mathrm{~mA} \mathrm{~h} \mathrm{~g}^{-1}$ after 100 cycles at a current density of $200 \mathrm{~mA} \mathrm{~g}^{-1}$. Electrochemical impedance spectroscopy (EIS) measurements prove that charge transfer resistance of PoSi/CMT composites is smaller than that of pure PoSi. In this study, we propose a quick, economical and feasible method to prepare silicon-based anode materials for lithium-ion batteries.
\end{abstract}

\section{Introduction}

Lithium-ion batteries have attracted increasing attention due to their prospective industrial applications. At present, lithiumion batteries occupy significant market shares of mobile phones, notebook computers, new energy vehicles, energy storage power stations, etc. ${ }^{\mathbf{1} 2}$ The current commercial lithium anode material is graphite, and its theoretical capacity is only $372 \mathrm{~mA} \mathrm{~h} \mathrm{~g}{ }^{-1},{ }^{3}$ which cannot meet the requirement of high energy density. To improve the energy density of weight and volume, ${ }^{4,5}$ various electrochemical active materials with high capacity have been investigated to replace graphite as anode materials of lithium-ion batteries.

According to different reaction mechanisms, the anode materials of lithium-ion batteries can be divided into three types: alloy reactive type, embedded type and structural transformation type. ${ }^{6}$ Among the alloy reactive materials, lithiumsilicon alloy shows the greatest utilization potential, because the theoretical discharge capacity of $\mathrm{Li}_{4.4} \mathrm{Si}$ alloy is as high as

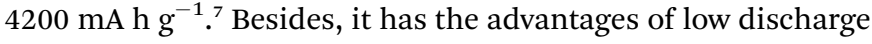
voltage and rich reserves in natural resources. However, in the

${ }^{a}$ State Key Laboratory of Silicon Materials, School of Materials Science and Engineering, Zhejiang University, Hangzhou 310027, P. R. China. E-mail: phy_wangl@zju.edu.cn

${ }^{b}$ Jiangsu Key Lab of Silicon Based Electronic Materials, Jiangsu GCL Silicon Material Technology Development Co., Ltd., Xuzhou, 22100o, P. R. China

${ }^{c}$ Bengbu Institute of Product Quality Supervision and Inspection Research, Bengbu, Anhui, 233000, P. R. China process of charging, the insertion of lithium ions causes volume expansion of silicon, which can reach 3.2 times that of the original volume. Huge volume expansion/constriction can cause great stress, which results in crushing and cracking of silicon materials; they instantly lose their effective electronic conduction, and this leads to rapid attenuation of the capacity. Moreover, the diffusion coefficient of lithium in a lithiumsilicon alloy is small; therefore, the conductivity of silicon is poor.

To solve the problem of poor conductivity of silicon, different carbon materials such as carbon nanotubes ${ }^{8-11}$ and graphene ${ }^{12-14}$ are often introduced into silicon anodes. Aiming to solve the problem of capacity instability caused by volume expansion of silicon, various methods such as carbon encapsulation and the preparation of nano silicon and porous silicon have been investigated. Besides, to promote electrical or thermal stability, porous Si materials have been designed to combine with conducting polymer and transition metal oxides. ${ }^{15-19}$ Among these methods, the de-alloying method is a useful way for preparing porous silicon with high electrochemical performance. Recently, Al-Si alloy has attracted much attention due to its low cost. Jiang et al. ${ }^{20}$ used an acidic etching solution to remove aluminium from aluminium-silicon ( $\mathrm{Al}-\mathrm{Si}$ ) alloys, leaving behind the silicon framework, which was porous silicon. Jinkui Feng et al. ${ }^{21}$ reacted $\mathrm{Al}-\mathrm{Si}$ alloys with $\mathrm{HCl}$ in a graphene oxide solution, and the graphene oxide was reduced to graphene in a hydrogen atmosphere after filtration. Therefore, porous silicon/graphene composites were prepared, and their capacity remained at $2000 \mathrm{~mA} \mathrm{~h} \mathrm{~g}^{-1}$ after 100 cycles. 
Takeshi Wada et al. ${ }^{22}$ synthesized nano porous silicon using dealloying in a metallic melt, which is a top-down process. When immersing $\mathrm{Mg}_{2} \mathrm{Si}$ precursor in a Bi melt, $\mathrm{Mg}$ can selectively dissolved from $\mathrm{Mg}_{2} \mathrm{Si}$ into the $\mathrm{Bi}$ melt, by the principle that $\mathrm{Mg}$ and $\mathrm{Bi}$ were solid solution to each other and $\mathrm{Si}$ and $\mathrm{Bi}$ were not solid solution to each other. Park et al. ${ }^{23}$ synthesized porous silicon by chemical etching of melt-spun $\mathrm{Si} / \mathrm{Al}-\mathrm{Cu}-\mathrm{Fe}$ alloy nanocomposites followed by carbonization using a pitch. The composite material still exhibited a capacity of $1000 \mathrm{~mA} \mathrm{~h} \mathrm{~g}{ }^{-1}$ or more after 100 cycles. The above study shows some advantages of the de-alloying method to obtain porous $\mathrm{Si}$ anode materials. However, it is still a challenge for the dealloying process of $\mathrm{Al}-\mathrm{Si}$ alloy to rapidly remove $\mathrm{Al}$ from $\mathrm{Si}$ alloy by easy chemical etching to attain a stable porous $\mathrm{Si}$ structure.

In this paper, we proposed a unique configuration of acid etching solution to resolve the problem of very long preparation time and incomplete removal of aluminium from Al-Si alloys; we design a simple and easy method to synthesize PoSi/CMTs, which is of great help in industrial applications because of reduction in time. In addition, the spherical $\mathrm{Al}-\mathrm{Si}$ alloys were employed to avoid the problem of easy collapse of the bulk porous silicon structure. This method is simple and feasible, which can be used to prepare PoSi/CMTs with high stability and good conductivity as anode materials for lithium-ion batteries.

\section{Experimental}

\section{Synthesis of porous silicon/carbon microtube composites}

The schematic process of experiments is shown in Fig. 1. A certain amount of Al-Si alloy powders (consisting of $80 \% \mathrm{Al}$, $20 \%$ Si, National Drug Chemical Reagents Co., Ltd) was added into $4.8 \mathrm{~mol} \mathrm{~L}^{-1} \mathrm{HCl}(\mathrm{AR})$, and a proper amount of $\mathrm{CuCl}_{2} \cdot 2 \mathrm{H}_{2} \mathrm{O}$ (AR, Aldrich) was added along with constant magnetic stirring. After aluminium was removed (about $2 \mathrm{~h}$ ), the composites were washed with deionized water for three times. After that, a mixture of porous silicon and copper particles was obtained by filtering and drying the sample in a vacuum oven at $80^{\circ} \mathrm{C}$. Then, the sample was placed in a tube furnace on a crucible and heattreated at $750{ }^{\circ} \mathrm{C}$ for 3 hours with the mix gas $\left(\mathrm{Ar}: \mathrm{C}_{2} \mathrm{H}_{2}=10: 1\right.$; the heating rate of the furnace is $\left.8{ }^{\circ} \mathrm{C} \min ^{-1}\right)$. Finally, the

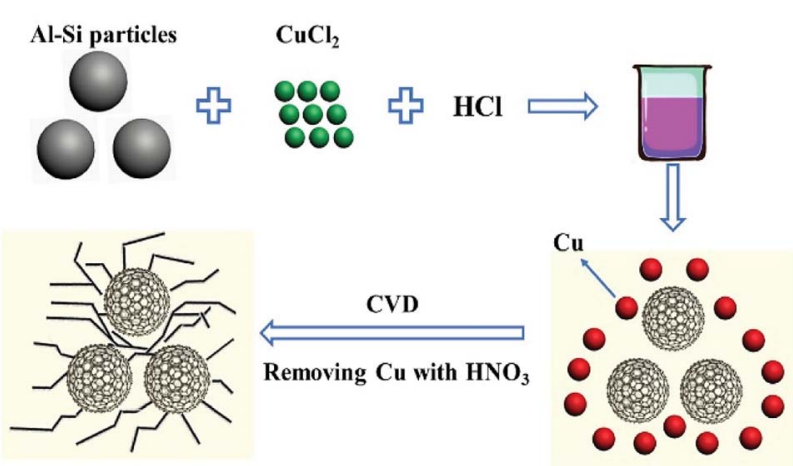

Fig. 1 Schematic illustration for the synthesis of PoSi/CMT particles. copper was removed from the product by 8.5 mol L ${ }^{-1} \mathrm{HNO}_{3}$ (AR).

\section{Characterization and electrochemical measurement}

The morphology of the samples was characterized by a field emission scanning electron microscope (FESEM, HITACHI $\mathrm{S} 4800$, the operating voltage is $5 \mathrm{kV}$ ) and a field emission transmission electron microscope (FEI TECNAI G2 F20, the operating voltage is $200 \mathrm{kV}$ ). X-ray diffraction (XRD) was performed on a Rigaku D/max-ga X-ray diffractometer with graphite monochromatized $\mathrm{Cu} \mathrm{K} \alpha$ radiation $(\lambda=1.54178 \AA$ ) $)$. The Raman analysis was conducted by a Jobin-Yvon's Lab Raman HR-800 UV laser Raman spectrometer. The argon source used for the test was 10 $\mathrm{mW}$ with a wavelength of $514.5 \mathrm{~nm}$. Brunauer-Emmett-Teller (BET) specific surface area and pore diameter distribution were determined from the results of $\mathrm{N}_{2}$ adsorption/desorption measurements using a Beckman Coulter Omnisorp 100cx. Thermogravimetric analysis (TGA) was conducted with SDT Q600 V8.2 Build 100. Active materials (PoSi/CMTs), sodium carboxymethyl cellulose (CMC) and conductive agent (SP) were mixed at a mass ratio of $7: 2: 1$ and stirred for 12 hours with deionized water. About $2 \mathrm{mg}$ of active material was coated on the copper foam. The electrode was placed in an argon-filled glovebox (Mbraun, Labstar, Germany) and assembled into a coin cell (2025-type) using a lithium foil as a counter electrode. The electrolyte was $1 \mathrm{M} \mathrm{LiPF}_{6}$ in the mixture of dimethyl carbonate (DMC) and ethylene carbonate (EC) (1:1 at volume ratio); 5 vol\% fluoroethylene carbonate was added to improve the cycling stability. All cells were cycled between 0.01 and $1.5 \mathrm{~V}$. The charge and discharge tests were performed in a Land battery test system (CT2001A of Wuhan Lanhe Electronics Co., Ltd.). The test system was equipped with a thermostat and a constant temperature of $35{ }^{\circ} \mathrm{C}$. For cyclic voltammetry, we used the LK2006A electrochemical workstation from Tianjin Lanli Chemical Electronic High Technology Co., Ltd.

\section{Results and discussion}

There are many reports about the de-alloying of Al-Si alloy by acid etching. ${ }^{\mathbf{2 0 , 2 1 , 2 4}}$ The key point is how to remove aluminum efficiently and to the utmost extent. It is difficult to quickly and completely remove $\mathrm{Al}$ from $\mathrm{Al}-\mathrm{Si}$ alloy with individual acid by traditional methods. Moreover, the porous structure of silicon after de-alloying can be destroyed by continuous stirring for a long time during the acid reaction. In this paper, we proposed to add $\mathrm{CuCl}_{2}$ as an etching promoter in the etchant $\mathrm{HCl}$ (the molar ratios of $\mathrm{Al}$ and $\mathrm{CuCl}_{2}$ are $12: 1,6: 1,3: 1$ and $1.5: 1$ ). Copper ions have weak oxidizing properties and can enter the $\mathrm{Al}-\mathrm{Si}$ alloy to make the reaction more complete. More importantly, the addition of $\mathrm{CuCl}_{2}$ can reduce the reaction time from more than 24 hours to 2 hours. The reduction of time is very important for industrial applications. Additionally, the porous silicon prepared by the $\mathrm{CuCl}_{2}$-assisted process has better chemical properties, which will be discussed below. XRD patterns of Al-Si alloys after etching with different proportions of $\mathrm{CuCl}_{2}$ in the etchant $\mathrm{HCl}$ are shown in Fig. 2a. It can be seen 
that not only $\mathrm{Cu}$, but also $\mathrm{Cu}_{2} \mathrm{O}$ is obtained, whereas only $\mathrm{Cu}$ is effective for the next-step process to produce CMTs. Furthermore, more $\mathrm{Cu}$ and less $\mathrm{Cu}_{2} \mathrm{O}$ are obtained when the molar ratio of $\mathrm{Al}$ and $\mathrm{CuCl}_{2}$ is $6: 1$. We can speculate that the following reactions occur during etching of the Al-Si alloy:

$$
\begin{gathered}
\mathrm{Al}+\mathrm{HCl} \rightarrow \mathrm{AlCl}_{3}+\mathrm{H}_{2} \\
\mathrm{Al}+\mathrm{CuCl}_{2} \rightarrow \mathrm{AlCl}_{3}+\mathrm{Cu}
\end{gathered}
$$

$$
\begin{gathered}
\mathrm{Cu}+\mathrm{O}_{2} \rightarrow \mathrm{CuO} \\
\mathrm{Cu}+\mathrm{CuO} \rightarrow \mathrm{Cu}_{2} \mathrm{O} \\
\mathrm{CuO}+\mathrm{HCl} \rightarrow \mathrm{CuCl}_{2}+\mathrm{H}_{2} \mathrm{O}
\end{gathered}
$$

Copper ions are weakly oxidizing and can oxidize aluminium to aluminium ions; thus, copper ions can be reduced to copper. $\mathrm{CuO}$ formed during the reaction is etched by $\mathrm{HCl}$ to form $\mathrm{CuCl}_{2}$
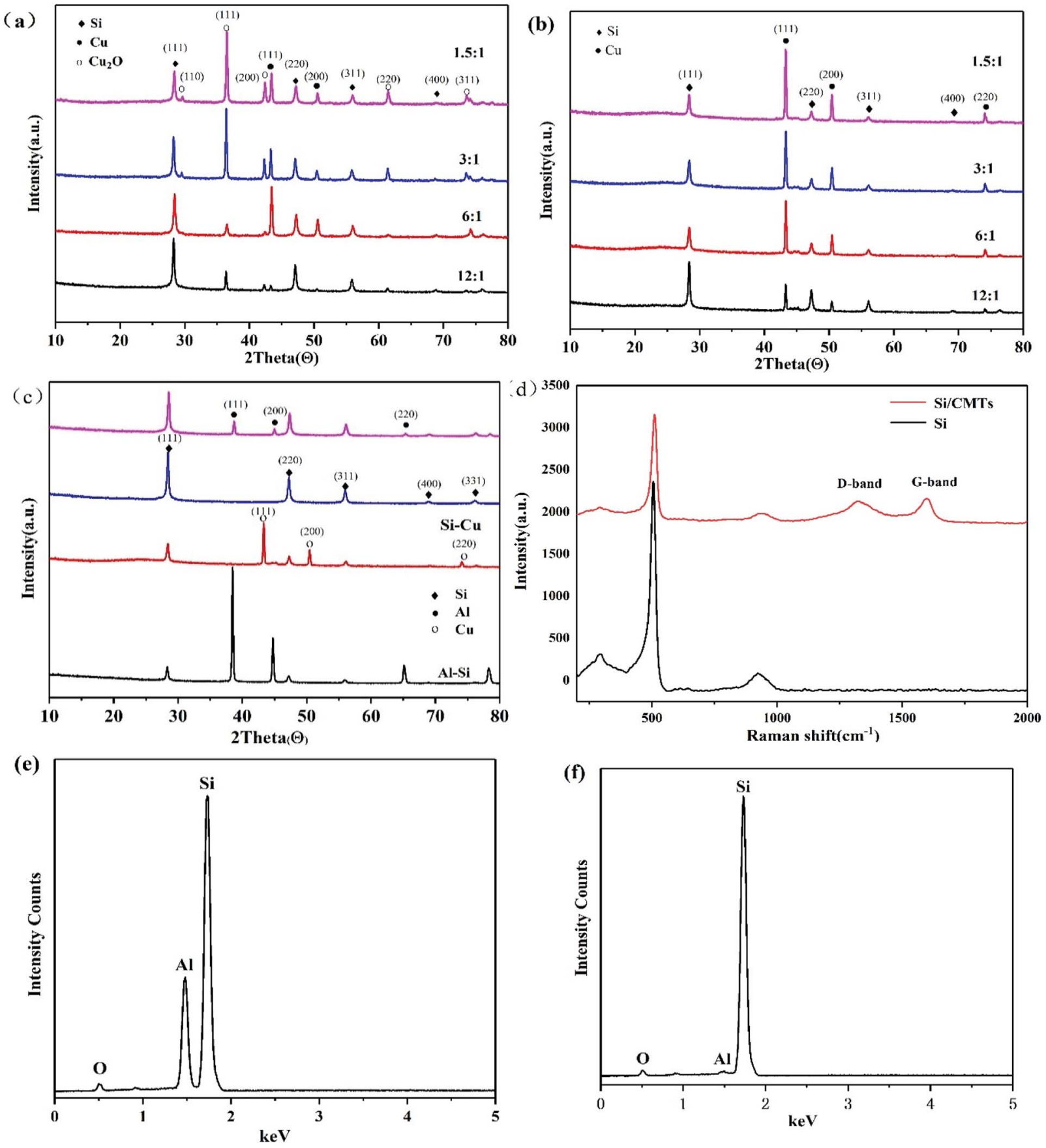

Fig. 2 XRD patterns of (a) Al-Si alloys after etching with different proportions of $\mathrm{CuCl}_{2}$ in the etchant $\mathrm{HCl}$; (b) samples after chemical vapor deposition; (c) Al-Si alloys that have undergone different processing steps. (d) Raman spectra of Si and PoSi/CMTs. EDX patterns of (e) Al-Si alloys after etching with $\mathrm{HCl}$ for $2 \mathrm{~h}$; (f) $\mathrm{Al}-\mathrm{Si}$ alloys after etching with $\mathrm{CuCl}_{2}$ and $\mathrm{HCl}$ for $2 \mathrm{~h}$ (the molar ratio of $\mathrm{Al}$ and $\mathrm{CuCl}_{2}$ is $6: 1$ ). 
again, as shown in eqn (5). This process continues until aluminium is eliminated. Residual copper in the form of an elementary substance or $\mathrm{Cu}_{2} \mathrm{O}$ can be easily removed by acid, which is removed after chemical vapour deposition because copper can be used as a catalyst for CMT formation. XRD patterns of samples after chemical vapour deposition in mixed gas are shown in Fig. 2b, which shows that $\mathrm{Cu}_{2} \mathrm{O}$ species in the samples are reduced to $\mathrm{Cu}$ by $\mathrm{C}_{2} \mathrm{H}_{2}$. Fig. 2c shows the XRD pattern of $\mathrm{Al}-\mathrm{Si}$ alloys that have undergone different processing steps. The first curve in Fig. 2c corresponds to the experiment in which only $\mathrm{HCl}$ is used to remove $\mathrm{Al}$ for 2 hours, and the second curve corresponds to the experiment in which both $\mathrm{HCl}$ and $\mathrm{CuCl}_{2}$ are used to remove $\mathrm{Al}$ for 2 hours. Combined with the EDX patterns in Fig. 2e and $\mathrm{f}$, it can be seen that the peak of aluminium can hardly be detected with the addition of $\mathrm{CuCl}_{2}$, indicating that aluminium is removed with the addition of $\mathrm{CuCl}_{2}$. After chemical vapour deposition, $\mathrm{Cu}$ is removed by nitric acid. Compared with the observation in the third curve in Fig. 2c, there is no copper peak in the second curve, indicating that $\mathrm{Cu}$ has also been removed. Fig. 2d shows the Raman spectra of Si and PoSi/CMT composites. For the PoSi/CMT composites, the curve has a highest peak at $511 \mathrm{~cm}^{-1}$, which is consistent with the characteristic peak of pure silicon. ${ }^{25}$ The peaks at around $1340 \mathrm{~cm}^{-1}$ and $1590 \mathrm{~cm}^{-1}$ (ref. 26) correspond to the disordered carbon or defect band ( $D$ band) and graphitic carbon band ( $\mathrm{G}$ band). The $\mathrm{D}$ band is related to disorder-allowed phonon modes, which becomes Raman active as a result of lack of long-range order in amorphous graphitic materials; the $\mathrm{G}$ band is associated with the allowed $\mathrm{E}_{2 \mathrm{~g}}$ optical modes of the Brillouin zone centre of crystalline graphite. ${ }^{27}$ It is generally accepted that the integrated intensity ratio of the $\mathrm{D}$ band and $\mathrm{G}$ band, i.e., $I_{\mathrm{D}} / I_{\mathrm{G}}$ depends on the structural characteristics of carbon. ${ }^{28}$ In the experiment, the $I_{\mathrm{D}} / I_{\mathrm{G}}$ ratio of PoSi/CMTs is calculated to be 2.1, suggesting high disorder of CMT materials.

The morphology and detailed microstructure of $\mathrm{Al}-\mathrm{Si}$, porous $\mathrm{Si}, \mathrm{CMT}$, and PoSi/CMT samples were investigated by FE-SEM and FE-TEM. As indicated in Fig. 3a, the as-received Al$\mathrm{Si}$ alloy particles are spherical with diameters of several micrometres. Fig. 3 b shows a mixture of porous silicon, $\mathrm{Cu}$ and $\mathrm{Cu}_{2} \mathrm{O}$ after the dealloying process. As seen from the figure, most of the porous silicon particles maintain a spherical structure; only a few of the spheres are broken, which is caused by tension produced by hydrogen gas released during dealloying. The morphology of porous silicon depends on the distribution of silicon in Al-Si alloys, most of which exhibit a network-like silicon structure. The angular and cubic particles that are agglomerated in the figure are $\mathrm{Cu}$ and $\mathrm{Cu}_{2} \mathrm{O} \cdot{ }^{29,30}$ After chemical vapor deposition, a large number of tubes (about $1 \mu \mathrm{m}$ in diameter) are produced and interlaced between the networklike silicon frameworks, as shown in Fig. 3c and d. Combined with the Raman analysis, we can infer that the generated tubes are carbon microtubes. From the XRD results, $\mathrm{Cu}$ particles are formed after etching, resulting in the formation of carbon microtubes in the CVD process. ${ }^{31}$ However, since the crystalline peaks of carbon are not apparent in the XRD pattern, it is speculated that the carbon microtubes are amorphous. TEM images of the bent, coiled carbon microtubes are shown in

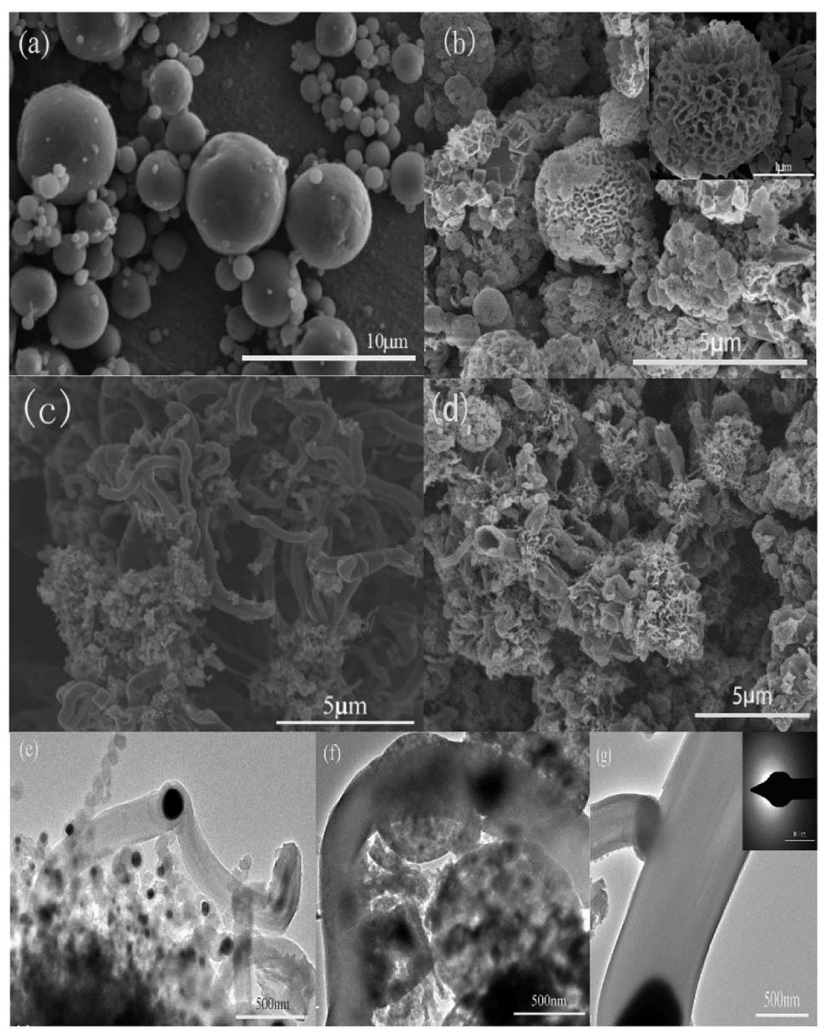

Fig. 3 SEM images of $\mathrm{Al}-\mathrm{Si}$ alloy particles (a), porous silicon/Cu/ $\mathrm{Cu}_{2} \mathrm{O}$ after etching (b) and PoSi/CMTs (c and d); TEM images of bent, coiled CMTs (e), PoSi/CMTs (f), and a CMT with the selected area electron diffraction (SAED) pattern in the inset (g).

Fig. 3e, the diameter of which is about $0.5-1 \mu \mathrm{m}$. Fig. 3f shows the three-dimensional structure of Si/CMT composite in which carbon microtubes are coiled on the surface of silicon particles. Selected area electron diffraction (SAED) modes for microtubes are presented in Fig. 3g; the diffuse pattern shows that the CMTs have typical amorphous features.

Fig. 4a-d show the TGA profiles of PoSi/CMTs fabricated with different proportions of $\mathrm{CuCl}_{2}$. There are two peaks in the TGA profiles, corresponding to a two-step decomposition of carbon material. The antioxidant capacity of the substance is related to the molecular structure of these carbon materials. CMTs and amorphous carbon are composed of $\mathrm{sp}^{2}$ carbon and $\mathrm{sp}^{3}$ carbon. ${ }^{32,33}$ The bond energy of $\mathrm{sp}^{2}$ carbon is higher than that of $\mathrm{sp}^{3}$ carbon; thus, $\mathrm{sp}^{2}$ carbon is thermodynamically more stable. ${ }^{34}$ Therefore, we speculate that $400-480{ }^{\circ} \mathrm{C}$ may mostly correspond to $\mathrm{sp}^{3}$ carbon, and $480-650{ }^{\circ} \mathrm{C}$ may mostly correspond to $\mathrm{sp}^{2}$ carbon. Except the mass ratios for the first group of samples, the mass ratios of CMTs and amorphous carbon are higher than $30 \%$. This has a slight negative effect on the capacity of PoSi/CMT composites but greatly increases the stability of capacity. Nitrogen adsorption-desorption measurements at $77 \mathrm{~K}$ are performed, as shown in Fig. 4e. The specific surface area of porous silicon is about $97 \mathrm{~m}^{2} \mathrm{~g}^{-1}$. The pore size distribution curve (Fig. 4f) shows that most of the pores have diameters of less than $100 \mathrm{~nm}$, and pore diameter of $20 \mathrm{~nm}$ is especially common. In the process of deintercalation/ intercalation of lithium, a large number of nanopores not 

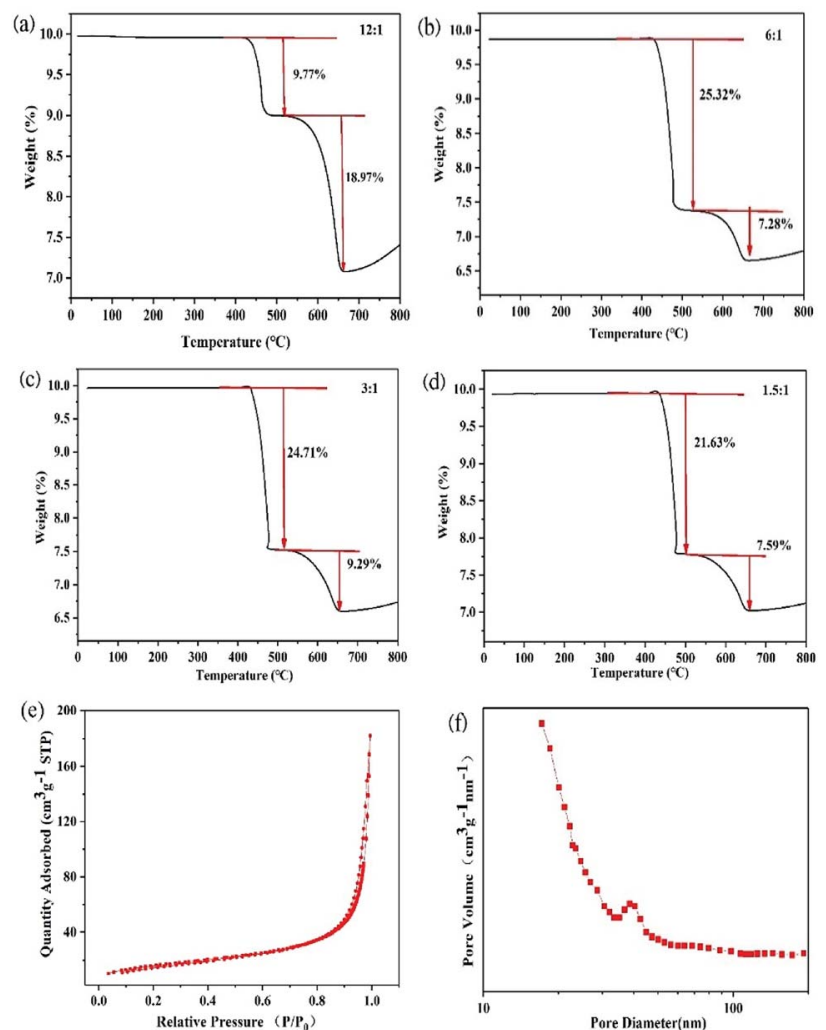

Fig. 4 Thermal stability curves (under compressed air gas) of (a) PoSi/ CMTs when the molar ratio of $\mathrm{Al}$ and $\mathrm{CuCl}_{2}$ is $12: 1$; (b) PoSi/CMTs when the molar ratio of $\mathrm{Al}$ and $\mathrm{CuCl}_{2}$ is $6: 1$; (c) PoSi/CMTs when the molar ratio of $\mathrm{Al}$ and $\mathrm{CuCl}_{2}$ is $3: 1$; (d) PoSi/CMTs when the molar ratio of $\mathrm{Al}$ and $\mathrm{CuCl}_{2}$ is $1.5: 1$. (e) Typical nitrogen adsorption-desorption curve of porous silicon. (f) Pore size distribution plot of porous silicon.

only increase the specific surface area of the material, which can allow the active material to contact the electrolyte quickly and easily, but also effectively relieve the stress caused by the volume expansion and contraction. In addition, the nanoscale pores can effectively shorten the lithium-ion diffusion distance and improve the material's rate performance; therefore, they exhibit more excellent performance.

Galvanostatic charge and discharge measurements were performed to evaluate the capacity and cycling life of PoSi/CMTs and $\mathrm{Si}$ at a current density of $200 \mathrm{~mA} \mathrm{~g}^{-1}$ between 0.01 and $1.5 \mathrm{~V}$. For comparison, part of charge-discharge voltage curves of PoSi/CMTs and Si is shown in Fig. 5a and b. From Fig. 5a, we can see lower and longer plateaus in the first discharge cycle due to the lithium alloying behaviour of crystalline silicon. Since silicon becomes amorphous after the first chargedischarge cycle, the shape of the curve will change and most of the curves overlap later in the cycle. The PoSi/CMT electrode demonstrates first reversible capacity of $2344 \mathrm{~mA} \mathrm{~h} \mathrm{~g}^{-1}$ with the first coulomb efficiency of $66 \%$. As a comparison, the initial reversible capacity of blank $\mathrm{Si}$ is $2315 \mathrm{~mA} \mathrm{~h} \mathrm{~g}{ }^{-1}$ and the first coulombic efficiency is $62 \%$. Clearly, PoSi/CMTs possess better specific capacity retention than blank $\mathrm{Si}$ because visible porous structures and CMTs can buffer the volume change. The low first coulomb efficiency can be due to the formation of the solid electrolyte interphase on the surface of the electrode ${ }^{35}$ and the irreversible loss of lithium at the first lithiation process such as electrolyte decomposition on carbon. ${ }^{36}$ Cycle performances of PoSi/CMTs and Si at a current density of $200 \mathrm{~mA} \mathrm{~g}^{-1}$ are displayed in Fig. 5c; all electrodes are cycled between 0.01 and $1.5 \mathrm{~V}$ at a current density of $200 \mathrm{~mA} \mathrm{~g}^{-1}$ for 100 cycles. For PoSi/CMTs, the first specific capacity is $2344 \mathrm{~mA} \mathrm{~h} \mathrm{~g}{ }^{-1}$, and the second specific capacity is $1545 \mathrm{~mA} \mathrm{~g}^{-1}$. The reversible capacity of PoSi/ CMT electrode remains at $1127 \mathrm{~mA} \mathrm{~h} \mathrm{~g}^{-1}$ after 100 cycles $(73 \%$ capacity retention). However, only a capacity of $283 \mathrm{~mA} \mathrm{~h} \mathrm{~g}^{-1}$ remains after 100 cycles for the blank silicon electrode. This is mainly due to the following reasons: (1) the porous structure buffers the volume expansion during the charge and discharge process. (2) The amorphous carbon layer on the porous silicon surface can reduce direct contact between the electrolyte and silicon, thus reducing irreversible lithium loss. (3) Carbon microtubes and amorphous carbon layers not only improve the conductivity but also provide some mitigation of volume expansion. ${ }^{37}$

In addition to good capacity retention, PoSi/CMT electrodes also demonstrate excellent rate capability, as shown in Fig. 5d. When the current density increases from $100 \mathrm{~mA} \mathrm{~g}^{-1}$ to 200 , $400,800,1000,2000$, and $3000 \mathrm{~mA} \mathrm{~g}^{-1}$, the reversible capacities of PoSi/CMTs correspond to $1712 \mathrm{~mA} \mathrm{~h} \mathrm{~g}^{-1}, 1566 \mathrm{~mA} \mathrm{~h} \mathrm{~g}^{-1}$, $1407 \mathrm{~mA} \mathrm{~h} \mathrm{~g}^{-1}, 1177 \mathrm{~mA} \mathrm{~h} \mathrm{~g}^{-1}, 1107 \mathrm{~mA} \mathrm{~h} \mathrm{~g}^{-1}, 798 \mathrm{~mA} \mathrm{~h} \mathrm{~g}^{-1}$, and $581 \mathrm{~mA} \mathrm{~h} \mathrm{~g}^{-1}$. The superior rate performances of the PoSi/ CMT electrodes are due to the porous structure of silicon and higher electrical conductivity of CMTs, which greatly reduce not only the internal resistance of electrode but also the fracture of electrode active materials. Cyclic voltammograms of PoSi/CMTs in a scanning range of $0.01-1.5 \mathrm{~V}$ and at a scanning rate of $0.1 \mathrm{mV} \mathrm{s}^{-1}$ are shown in Fig. 5e. It is shown from the first negative scan that the irreversible peak of electrolyte decomposition ranging from 0.5 to $1.1 \mathrm{~V}$ barely appears, which indicates that the electrolyte decomposition on the surface is inhibited by the amorphous carbon coating on silicon. ${ }^{38}$ Cycle peak increases below $0.3 \mathrm{~V}$ and corresponds to the cathodic lithiation of crystalline $\mathrm{Si}$ to form $\mathrm{Li}_{x} \mathrm{Si}$. In the positive scan, both the anodic peaks at $0.3 \mathrm{~V}$ and $0.5 \mathrm{~V}$ correspond to the delithiation of $\mathrm{Li}_{x} \mathrm{Si}$ back to Si. The cathodic peak appearing between $0.3 \mathrm{~V}$ and $0.1 \mathrm{~V}$ in the second cycle is mainly caused by the intercalation of amorphous carbon and amorphous silicon. The peaks at $0.3 \mathrm{~V}$ and $0.5 \mathrm{~V}$ and the peak between $0.3 \mathrm{~V}$ and $0.1 \mathrm{~V}$ become broader and stronger gradually after the initial cycle owing to the gradual activation of $\mathrm{Si}$ and degradation of $\mathrm{Si}$ crystallinity. To better comprehend the superior electrochemical performance of PoSi/CMTs compared with that of blank Si, EIS at the open-circuit voltage is performed (Fig. 5f). The high-frequency semicircle is in accordance with the chargetransfer resistance $\left(R_{\mathrm{ct}}\right)$ and double-layer capacitance at the interface between the electrolyte and electrode. The angle of the inclined line corresponds to the rate of lithium-ion diffusion process. ${ }^{39,40}$ The semicircle diameter of PoSi/CMTs is smaller than that of blank silicon, indicating that PoSi/CMTs have smaller charge transfer resistance. These experimental results demonstrate that CMTs and amorphous carbon layers can increase the rate of electron transport, thus increasing the rate of intercalation and deintercalation of lithium ions. Therefore, 
(a)

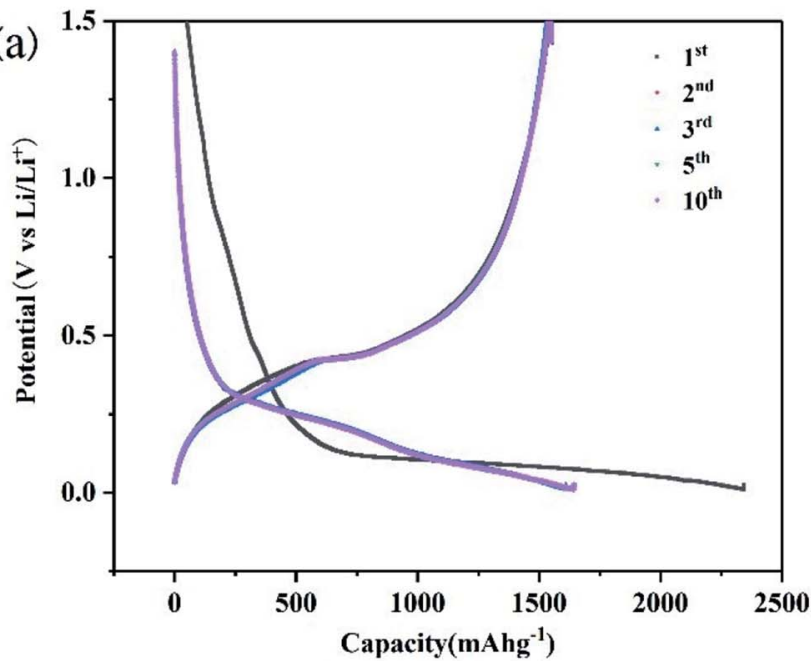

(c)

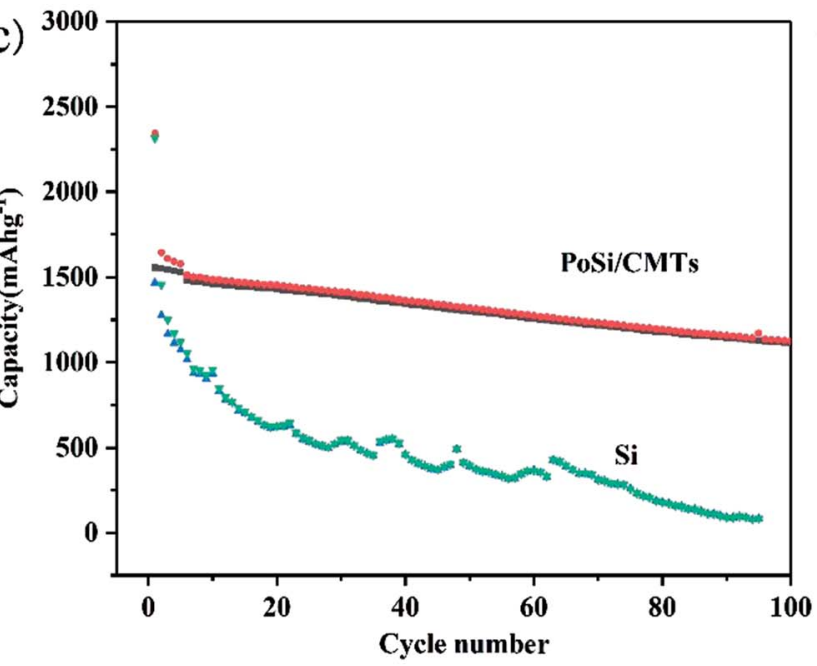

(e)

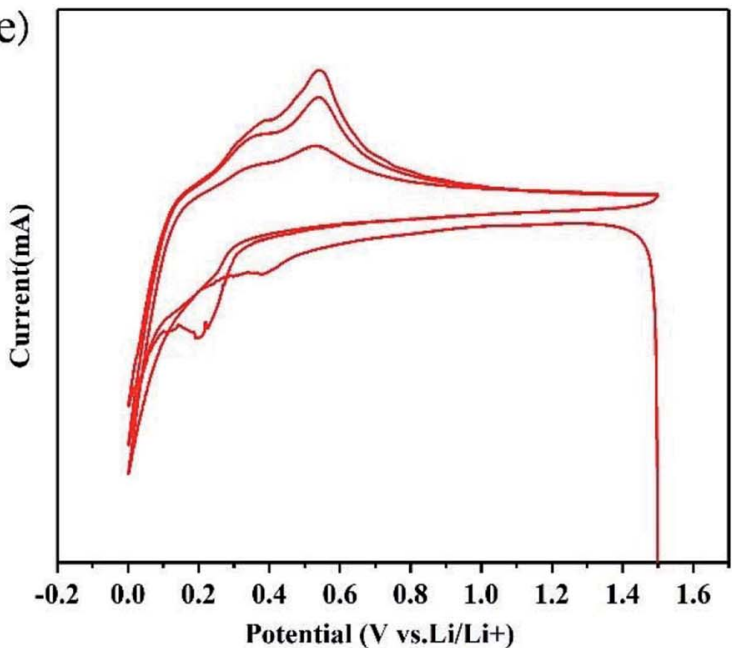

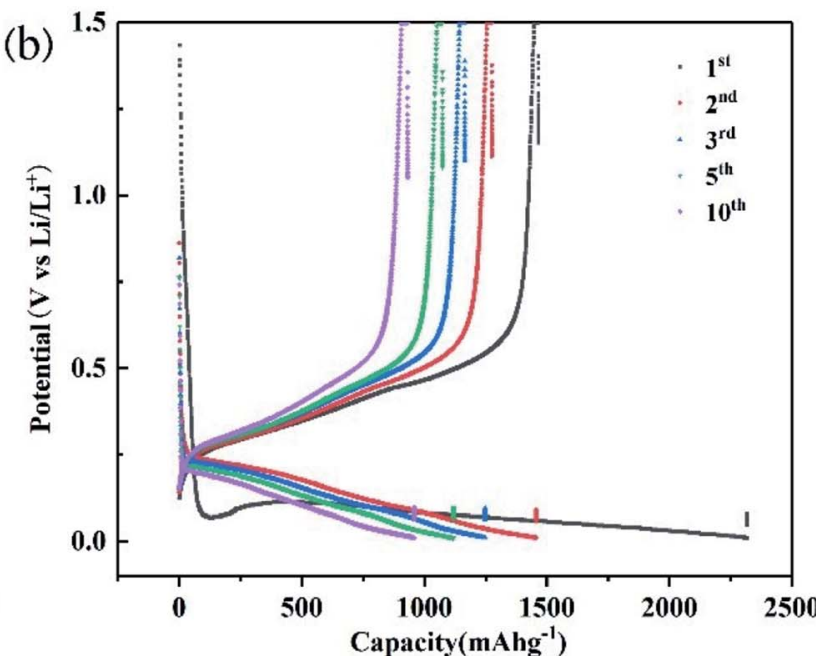

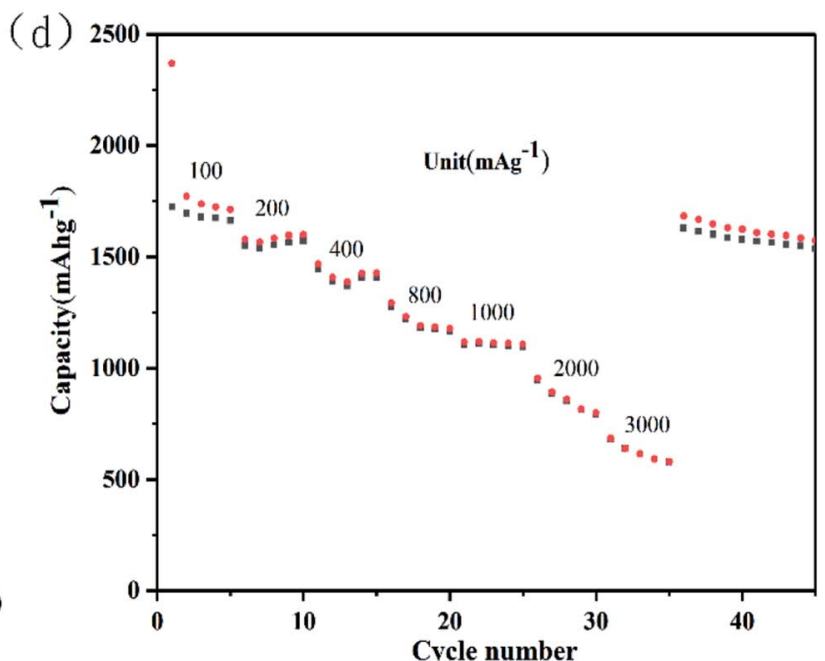

(f)

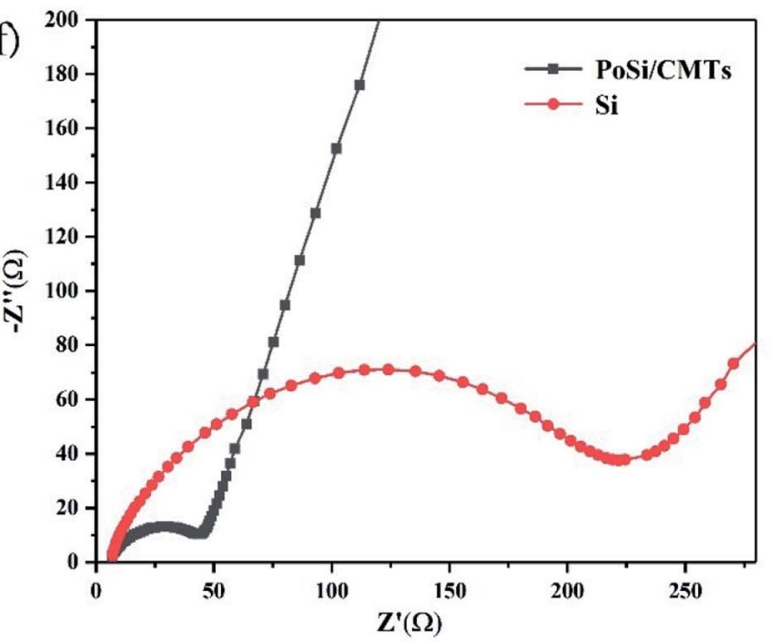

Fig. 5 Part of charge-discharge voltage curves of (a) PoSi/CMTs; (b) Si at $200 \mathrm{~mA} \mathrm{~g}^{-1}$ from 0.01 to $1.5 \mathrm{~V}$. (c) Cycle performances of the PoSi/ CMTs and Si at a current density of $200 \mathrm{~mA} \mathrm{~g}^{-1}$. (d) Rate performance of PoSi/CMTs and Si at current densities of 100, 200, 400, 800, 1000, 2000 and $3000 \mathrm{~mA} \mathrm{~g}^{-1}$. (e) Cyclic voltammograms of PoSi/CMTs in a scanning range of $0.01-1.5 \mathrm{~V}$ and at a scanning rate of $0.1 \mathrm{mV} \mathrm{s}{ }^{-1}$. (f) Electrochemical impedance spectroscopy of PoSi/CMTs and Si.

PoSi/CMTs display excellent electrochemical performance with stable cycle performance and superior rate performance.
In addition, we also compared the cyclic properties of porous silicon materials prepared by conventional etching processes and those of porous silicon materials prepared by $\mathrm{CuCl}_{2}$-assisted 


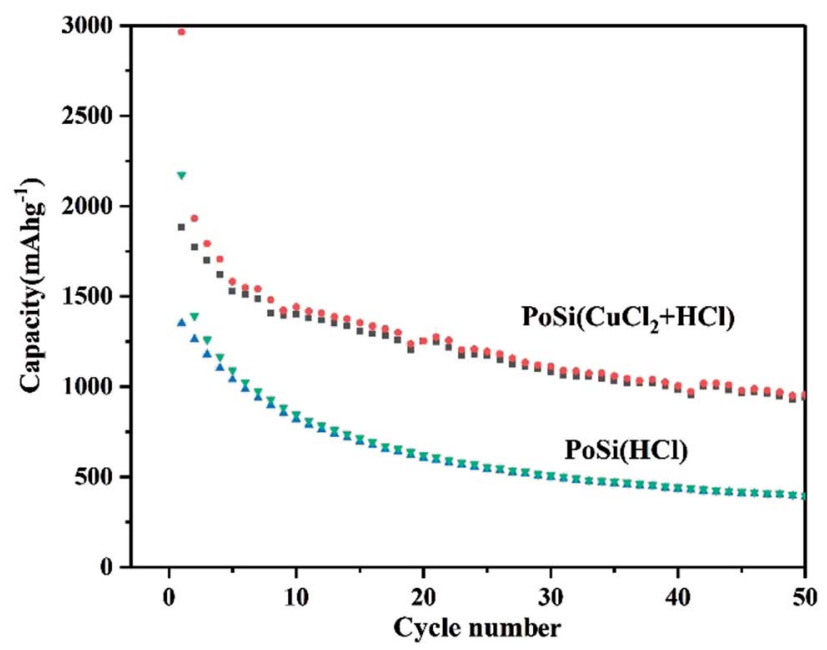

Fig. 6 Cycle performances of the porous silicon prepared by different processes at a current density of $200 \mathrm{~mA} \mathrm{~g}^{-1}$.

process, as shown in Fig. 6. For the porous silicon materials prepared by $\mathrm{CuCl}_{2}$-assisted process, the first specific capacity is $2963 \mathrm{~mA} \mathrm{~h} \mathrm{~g}^{-1}$, and the second specific capacity is $1880 \mathrm{~mA} \mathrm{~g}^{-1}$. The reversible capacity drops to $945 \mathrm{~mA} \mathrm{~h}^{-1}$ after 50 cycles $(50 \%$ capacity retention). Compared with the capacity retention ratio of $73 \%$ of PoSi/CMTs, it is indicated that CMTs and amorphous carbon do contribute to the increase in the stability of the porous silicon. However, for porous silicon prepared by a conventional etching process, the first specific capacity is $2173 \mathrm{~mA} \mathrm{~h} \mathrm{~g}^{-1}$, and the second specific capacity is $1351 \mathrm{~mA} \mathrm{~g}^{-1}$. The reversible capacity drops to $393 \mathrm{~mA} \mathrm{~h} \mathrm{~g}^{-1}$ after 50 cycles. The reason for the low capacity of porous silicon prepared by the conventional process is that the aluminium removal is incomplete.

\section{Conclusion}

A simple and rapid method to synthesize PoSi/CMTs from Al-Si alloy powders is proposed including three main steps: $\mathrm{HCl}$ and $\mathrm{CuCl}_{2}$ solution etching, CVD treatment by $\mathrm{Ar}$ and $\mathrm{C}_{2} \mathrm{H}_{2}$ mix gas and $\mathrm{HNO}_{3}$ cleaning. The products have a stable porous structure and negligible metal residues. CMTs can act as both conductive agent and buffer for Si volume change during the charge and discharge process. The prototype battery device shows high reversible capacity and excellent rate capability, which can be ascribed to the structure, where porous silicon powders are wrapped by a network of interwoven carbon microtubes and amorphous carbon layers.

\section{Conflicts of interest}

There are no conflicts to declare.

\section{Acknowledgements}

This work was supported by the National Science Foundation of China (No. 51532007, 61721005), the Fundamental Research
Funds for the Central Universities (No. 2017FZA4005) and Key Project of Zhejiang Province (No. 2018C01034).

\section{Notes and references}

1 B. Scrosati, J. Hassoun and Y.-K. Sun, Energy Environ. Sci., 2011, 4, 3287-3295.

2 Y. Hu and X. Sun, J. Mater. Chem. A, 2014, 2, 10712-10738.

3 X. Zuo, J. Zhu, P. Müller-Buschbaum and Y.-J. Cheng, Nano Energy, 2017, 31, 113-143.

4 Y.-S. He, P. Gao, J. Chen, X. Yang, X.-Z. Liao, J. Yang and Z.-F. Ma, RSC Adv., 2011, 1, 958-960.

5 M. Ge, X. Fang, J. Rong and C. Zhou, Nanotechnology, 2013, 24, 422001.

6 M. R. Palacin, Chem. Soc. Rev., 2009, 38, 2565-2575.

7 D. Molina Piper, T. Evans, S. Xu, S. C. Kim, S. S. Han, K. L. Liu, K. H. Oh, R. Yang and S. H. Lee, Adv. Mater., 2016, 28, 188-193.

8 H. Wu, G. Zheng, N. Liu, T. J. Carney, Y. Yang and Y. Cui, Nano Lett., 2012, 12, 904-909.

9 W. Weng, H. Lin, X. Chen, J. Ren, Z. Zhang, L. Qiu, G. Guan and H. Peng, J. Mater. Chem. A, 2014, 2, 9306.

10 Y. Li, M. Li, M. Pang, S. Feng, J. Zhang and C. Zhang, J. Mater. Chem. C, 2015, 3, 5573-5579.

11 C. Zhai, N. Du, H. Zhang, J. Yu, P. Wu, C. Xiao and D. Yang, Nanoscale, 2011, 3, 1798-1801.

12 X. Zhao, C. M. Hayner, M. C. Kung and H. H. Kung, Adv. Energy Mater., 2011, 1, 1079-1084.

13 N. Lin, J. Zhou, Y. Zhu and Y. Qian, J. Mater. Chem. A, 2014, 2, 19604-19608.

14 L. Shi and T. Zhao, J. Mater. Chem. A, 2017, 5, 3735-3758.

15 J.-G. Kim, G. Jeong, M.-S. Park, M. Seo, S. M. Hwang, Y.-U. Kim, Y.-J. Kim, J. H. Kim and S. X. Dou, ACS Nano, 2014, 8, 2977-2985.

16 H. Y. Eunjun Park, J. Lee, M.-S. Park, Y.-J. Kim and H. Kim, ACS Nano, 2015, 9, 7690-7696.

17 E. Park, J. Kim, D. J. Chung, M. S. Park, H. Kim and J. H. Kim, ChemSusChem, 2016, 9, 2754-2758.

18 J. Kim, J. H. Kim and K. Ariga, Joule, 2017, 1, 739-768.

19 H. Jung, Y.-U. Kim, M.-S. Sung, Y. Hwa, G. Jeong, G.-B. Kim and H.-J. Sohn, J. Mater. Chem., 2011, 21, 11213-11216.

20 Z. Jiang, C. Li, S. Hao, K. Zhu and P. Zhang, Electrochim. Acta, 2014, 115, 393-398.

21 J. Feng, Z. Zhang, L. Ci, W. Zhai, Q. Ai and S. Xiong, J. Power Sources, 2015, 287, 177-183.

22 T. Wada, T. Ichitsubo, K. Yubuta, H. Segawa, H. Yoshida and H. Kato, Nano Lett., 2014, 14, 4505-4510.

23 H. I. Park, M. Sohn, D. S. Kim, C. Park, J. H. Choi and H. Kim, ChemSusChem, 2016, 9, 834-840.

24 W. Zhai, Q. Ai, L. Chen, S. Wei, D. Li, L. Zhang, P. Si, J. Feng and L. Ci, Nano Res., 2017, 10, 4274-4283.

25 J. Bonse, K. W. Brzezinka and A. J. Meixner, Appl. Surf. Sci., 2004, 221, 215-230.

26 M. Yoshikawa, G. Katagiri, H. Ishida, A. Ishitani and T. Akamatsu, Appl. Phys. Lett., 1988, 52, 1639-1641.

27 H. S. Zhu, J. T. Jiu, F. Qiang, W. Hao and C. B. Cao, J. Mater. Sci., 2003, 38, 141-145. 
28 J. Kastner, T. Pichler, H. Kuzmany, S. Curran, W. Blau, D. N. Weldon, M. Delamesiere, S. Draper and H. Zandbergen, Chem. Phys. Lett., 1994, 221, 53-58.

29 F. Fievet, F. Fievet-Vincen, J.-P. Lagier, B. Dumont and M. Figlarz, J. Mater. Chem., 1998, 3, 627-632.

30 R. Bakthavatsalam and J. Kundu, CrystEngComm, 2017, 19, 1669-1679.

31 Y. Han, J. Zhou, J. Dong and K. Yoshiyuki, Phys. Chem. Chem. Phys., 2013, 15, 17171-17178.

32 X. Wang, X. Liu, L. Lai, S. Li, J. Weng, Z. Zhou, Q. Cui, X. Chen, M. Cao and Q. Zhang, Adv. Funct. Mater., 2008, 18, 1809-1823.

33 K. Sato, M. Noguchi and A. Demachi, Science, 1994, 264(5158), 556-558.
34 G. Dearnaley, Phys. Bull., 1980, 31, 359.

35 M. N. Obrovac and V. L. Chevrier, Chem. Rev., 2014, 114, 11444-11502.

36 S. H. Ng, J. Wang, D. Wexler, K. Konstantinov, Z. P. Guo and H. K. Liu, Angew. Chem., Int. Ed. Engl., 2006, 45, 6896-6899.

37 L. Shen, Z. Wang and L. Chen, RSC Adv., 2014, 4, 1531415318.

38 M. Yoshio, H. Y. Wang, K. Fukuda, T. Umeno, N. Dimov and Z. Ogumi, J. Electrochem. Soc., 2002, 149, A1598-A1603.

39 F. Maroni, R. Raccichini, A. Birrozzi, G. Carbonari, R. Tossici, F. Croce, R. Marassi and F. Nobili, J. Power Sources, 2014, 269, 873-882.

40 S. A. Klankowski, G. P. Pandey, B. A. Cruden, J. Liu, J. Wu, R. A. Rojeski and J. Li, J. Power Sources, 2015, 276, 73-79. 